\title{
Prólogo. \\ Veinte años por el hilo de la fábula
}

Adriana Cristina Crolla

Universidad Nacional del Litoral

El 2020 nos ha enfrentado al tsunami de la pandemia del Coronavirus y todo lo sólido que nos servía de anclaje y confort, se nos ha disuelto. No solo en el aire, como bien constató Karl Marx en el traspaso de la modernidad decimonónica a las experiencias disolutorias del siglo XX, sino hacia una modernidad líquida sin fronteras y con turbulentas y profundas contracorrientes. Porque si el aire en suspensión todavía servía de mullido sostén para pensarnos a fines del siglo XX, aun cuando sus hilachas o sus «babas del diablo» (Cortázar dixit) entretejían una danza desconfigurada y asfixiante, el siglo XXI nos lanzó abruptamente a la experiencia de la modernidad «líquida». La que según el sociólogo Bauman (2003) ${ }^{1}$ es el resultado de un cambio de paradigmas y de pasaje de la modernidad sólida (estable, repetitiva) a la líquida (flexible, voluble), que empezó a gestarse luego del terremoto de 1755 de Lisboa y del incendio posterior que terminó por arrasar lo poco que quedaba de la ciudad.

Para Bauman esta tragedia natural fue una catástrofe enorme, no solo material sino también intelectual porque la gente, que había sido educada para pensar que Dios, creador de la naturaleza, había planeado leyes inconmovibles y creíbles, se da cuenta de que esta es ciega, indiferente y hostil a los humanos. Y que era necesario que el hombre, con el auxilio de la razón, tomara las riendas de la administración del mundo. Así Rousseau y Voltaire vieron que el antiguo régimen ya no funcionaba y decidieron que había que fundirlo y rehacerlo de nuevo en el molde de la racionalidad. Para eso apostaron a la idea de una modernidad sólida, pensada en términos de resistencia para sustituir lo oxidado. La modernidad de las grandes fábricas, los sólidos empleos para muchos, en enormes edificios-fortalezas erigidos para resistir más tiempo que las catedrales góticas.

\footnotetext{
- Cavaliere della Repubblica Italiana, Ordine della Stella d'Italia. Magister en Docencia Universitaria. Profesora de Letras y de Italiano (FHUC, UNL - UADER). Directora del Centro de Estudios Comparados. Creadora y directora de El hilo de la fábula y de/ Portal Virtual de la Memoria Gringa http://www.fhuc.unl.edu. ar/portalgringo/crear/gringa/index_e.html. Directora del Programa de Estudios sobre Migraciones «Lina y Charles Beck Bernard». Especialista en italianística y francesística, inmigración y estudios comparados.
} 
Pero el siglo XX, con sus levedades y ramalazos de disolución, nos fue preparando para un presente en que dichas fortalezas se caen como panales de papel por fuerzas inesperadas e incontrolables (las torres gemelas de Manhattan implotadas desde el corazón mismo de ese caparazón de acero que, según los diseñadores, prometía estabilidad perenne a su colosal altura). O la implosión y jaque mate a la razón humana y a las quimeras de la modernidad a que dio lugar el tajeado vientre del Titanic en aquella aciaga noche de 1912, cuando un simple iceberg — predecible aunque tozudamente negado por la prepotencia titanística — canceló para siempre la utopía de la eterna flotabilidad. $\mathrm{O}$ a lo que es igual: al hombre alcanzando la divinidad.

Estamos sufriendo las consecuencias de una modernidad líquida, una sociedad líquida y un amor líquido donde todas las realidades (trabajo, redes de contención, matrimonio, regulaciones económicas, geopolítica, relaciones, marcos y fronteras) se han desvanecido. Lindes lábiles que dan paso a un mundo más precario, provisional, ansioso de novedades y, con frecuencia, agotador. Y ante lo que estamos sufriendo, soberanamente aterrador.

Pues bien, sin el auxilio de la razón ni las seguridades en las leves configuraciones entretejidas en el siglo anterior, es nuestro deber hoy, hallar el modo —o la nave- que nos permita flotar y encontrar algún anclaje posible en esta realidad cambiante, inestable, flexible, disolutoria, que, como el agua en el vaso, al menor movimiento cambia de forma y de sentido. Se trata de proponer para este mundo casi irreconocible y en disgregación, un grano de hospitalidad y de referencia. Si nada podemos cambiar, debemos oponer entonces la libertad a la impotencia, la acción a la anomia, el aprendizaje a la nada, la traza a la disgregación.

Un modo de parapetarnos y de demostrar el auxilio que nos brindan determinados anclajes intelectuales e interpretativos, como es el caso de los estudios comparados, es celebrar una trama ejecutada a la luz de un hilo que sin interrupciones ni altibajos fue tejiendo la fábula de esta revista.

Este número constituye la culminación de un ciclo que comenzara en 1999 en el seno del Centro de Estudios Comparados y que quedó patentizado en 20 números impresos gracias al apoyo económico de la Facultad de Humanidades y Ciencias y al apoyo editorial del Centro de Publicaciones de la Universidad Nacional del Litoral. Este vigésimo número, ya se nos comunicó, será el último de la serie impresa. Luego, a la luz de las nuevas tecnologías comunicativas, la revista garantiza su permanencia a través de la virtualidad. Perdiendo la belleza y simbolismo de su diseño gráfico pero ganando, seguramente, en expansión difusional.

Agradecemos a los más de 60 especialistas de primer nivel que a lo largo de estas dos décadas fueron aceptando con gran generosidad integrar el Comité Honorario y el Científico. Sus ámbitos académicos de pertenencia corresponden a 35 universidades diferentes del país y del exterior, cuatro centros e institutos de estudios —entre ellos el CONICET - y a la Fundación Internacional Borges.

Las páginas de la revista dan cuenta del aporte de 317 autores de 242 trabajos, 11 dossier con 54 colaboraciones y 77 glosas (reseñas). La revista integra hoy el catálogo de las redes más importantes de indexación de revistas científicas en Latinoamérica y ha sido evaluada por dos veces consecutivas con el Nivel 1 por el CONICET. Desde el ranking 2018 de la REDIB (Red Iberoamericana de Innovación y Conocimiento Científico) ocupa el puesto 600 en el mundo, es la tercera de las únicas cuatro rankeadas en Argentina e integra la terna que la Redib reconoce de las revistas de humanidades editadas por la UNL (https://redib.org/recursos/Ranking/Revistas). 
Es mucha la satisfacción por el recorrido y los logros alcanzados y la riqueza de lecturas sobre los estudios comparados que brinda la revista. También el agradecimiento a los veinte especialistas que aceptaron acompañarnos en este número aniversario, y a María Kodama al permitir «apropiarnos» de un título para nombrar la revista y acompañarnos junto al Borges comparatista avant la lettre que gustamos celebrar.

Finalmente, agradecemos a la investigadora y poeta Susana Romano Sued, quien nos acompaña con sus sabios consejos y entusiasta apoyo desde los momentos inaugurales del Centro de Estudios Comparados en 1995. Su obsequio es este especial soneto:

Homenaje al número veinte de El hilo de la Fábula por Susana Romano Sued

Cuando el tiempo es otro, como ahora

y es el mismo tal vez en la memoria

paso Revista al Hilo de la historia

con pasión de cotejos sin demora

Impulsos de migrancias, de saberes,

que entre las tantas otras son Morada:

la escena heteroglósica cuidada

brinda espacios retoños, como Ceres

Digitales algoritmos vencedores

la inversa de Gutenberg alientan

desde el Hilo corpóreo de la imprenta

Al laberinto de pantallas los lectores

despedida y convite a los autores:

¡Virtual la bienvenida, siempre atenta!

\section{Notas}

${ }^{1}$ Bauman, Z. (2003). Modernidad líquida. Fondo de Cultura Económica 